Article

\title{
Antimicrobial Activity of Six International Artisanal Kefirs against Bacillus cereus, Listeria monocytogenes, Salmonella enterica Serovar Enteritidis, and Staphylococcus aureus
}

\author{
Abrar Sindi ${ }^{1}$, Md. Bahadur Badsha ${ }^{2}$, Barbara Nielsen ${ }^{1}$ and Gülhan Ünlü ${ }^{1,3,4, * \mathbb{C}}$ \\ 1 School of Food Science, University of Idaho, 875 Perimeter Drive, MS 2312, Moscow, ID 83844-2312, USA; \\ sind3904@vandals.uidaho.edu (A.S.); barbn@uidaho.edu (B.N.) \\ 2 Institute for Modeling Collaboration and Innovation (IMCI), University of Idaho, 875 Perimeter Drive, \\ MS 1122, Moscow, ID 83844-1122, USA; mdbadsha@uidaho.edu \\ 3 School of Food Science, Washington State University, Pullman, WA 99164-6376, USA \\ 4 Department of Biological Engineering, University of Idaho, 875 Perimeter Drive, MS 2312, \\ Moscow, ID 83844-0904, USA \\ * Correspondence: gulhan@uidaho.edu; Tel.: +1-208-885-7771; Fax: +1-208-885-2567
}

Received: 29 April 2020; Accepted: 2 June 2020; Published: 4 June 2020

\begin{abstract}
Kefir, a fermented dairy beverage, exhibits antimicrobial activity due to many metabolic products, including bacteriocins, generated by lactic acid bacteria. In this study, the antimicrobial activities of artisanal kefir products from Fusion Tea (A), Britain (B), Ireland (I), Lithuania $(\mathrm{L})$, the Caucuses region $(\mathrm{C})$, and South Korea $(\mathrm{K})$ were investigated against select foodborne pathogens. Listeria monocytogenes CWD 1198, Salmonella enterica serovar Enteritidis ATCC 13076, Staphylococcus aureus ATCC 25923, and Bacillus cereus ATCC 14579 were inhibited by artisanal kefirs made with kefir grains from diverse origins. Kefirs A, B, and I inhibited all bacterial indicator strains examined at varying levels, except Escherichia coli ATCC 12435 (non-pathogenic, negative control). Kefirs K, L, and C inhibited all indicator strains, except S. aureus ATCC 25923 and E. coli ATCC 12435. Bacteriocins present in artisanal kefirs were determined to be the main antimicrobials in all kefirs examined. Kefir-based antimicrobials are being proposed as promising natural biopreservatives as per the results of the study.
\end{abstract}

Keywords: artisanal kefir; kefir product; kefir grain; natural antimicrobial; bacteriocin; Listeria monocytogenes; Salmonella enterica serovar Enteritidis; Staphylococcus aureus; Bacillus cereus

\section{Introduction}

Foodborne illnesses represent a significant public health challenge worldwide, with almost 1 in 10 people becoming sick and 33 million people dying [1]. Foodborne pathogens also have a huge impact on the economy. According to the World Bank Organization, the total productivity loss related to foodborne disease in low- and middle-income countries is valued at $\$ 95.2$ billion per year, in addition to the annual cost of $\$ 15$ billion used to treat affected individuals [2].

The Center for Disease Control and Prevention (CDC) estimates numbers for foodborne illness each year in the United States at 47.8 million cases, with 128,000 hospitalizations, 3030 deaths, and $\$ 78$ billion in cost, including the costs attributed to premature deaths, medical expenses, and loss of productivity. Unspecified pathogens cause $80 \%$ of the illnesses (38.4 million illnesses, 72,000 hospitalizations, and 1686 deaths) [3]. Known pathogens are responsible for $20 \%$ of the illnesses, estimated at 9.4 million illnesses, 59,961 hospitalizations, and 1351 deaths [4]. Of these, $90 \%$ have been linked to just 
seven microorganisms: Campylobacter sp., Clostridium perfringens, Escherichia coli (Serotype O157:H7), Listeria monocytogenes, Salmonella (non-typhoidal), norovirus, and Toxoplasma gondii. Non-typhoidal Salmonella was determined to be the principal cause of hospitalization and death among these seven pathogens [5].

Disability-adjusted life year (DALY) is a measure developed by the World Health Organization [1]. The DALY pools data on premature mortality and morbidity from acute illness and long-term sequelae into a single statistic, which in turn synopsizes years of healthy life lost. Scallan et al. [5] explored the overall impact of foodborne illness caused by the seven leading foodborne pathogens in the United States using DALY. They defined health states (acute illness and long-term sequelae) for each foodborne pathogen and then estimated the average annual incidence of each health state using data from public health surveillance and previously published estimates. These seven foodborne pathogens caused about 112,000 DALYs on an annual basis due to foodborne illnesses acquired in the United States. Non-typhoidal Salmonella $(32,900)$ and Toxoplasma gondii $(32,700)$ caused the most DALYs, trailed by Campylobacter sp. (22,500), norovirus (9900), L. monocytogenes (8800), C. perfringens (4000), and E. coli O157:H7 (1200). Among all foodborne pathogenic bacteria that can cause foodborne illness, non-typhoidal Salmonella and L. monocytogenes are responsible for 42,900 DALYs total (37\% of all DALYs). These two organisms are included as target organisms in the presented work. As a foodborne pathogen, Bacillus cereus is estimated to cause 63,623 foodborne disease cases per year in the United States [4,6]. Staphylococcal food poisoning accounts for about 241,994 foodborne disease cases per year in the United States [6]. B. cereus and S. aureus are also included in our work because foodborne illness caused by these organisms are highly underreported and underdiagnosed [6].

Reducing foodborne illness takes a great deal of time, effort, and collaboration. The ultimate goal for most public health and food safety officials worldwide is not just stopping foodborne illness outbreaks once they occur but also preventing them from happening in the first place. Long-term prevention of foodborne illness outbreaks takes the actions of countless partners in the food production chain stretching from farm to table: production, harvest, storage, processing, distribution, and preparation. Chemical preservation, biologically based preservation, and physical methods of food preservation are all used, individually and in combination, to inhibit foodborne pathogens in food processing.

Biologically based preservation methods are among the newer and emerging forms of food preservation. According to Matthews et al., "biopreservation is the use of lactic acid bacteria (LAB), their metabolic products, or both to improve or ensure the safety and quality of products that are not fermented" $[7,8]$. Some LAB produce antimicrobial peptides called bacteriocins which have been shown to inhibit foodborne pathogenic bacteria. Bacteriocins are ribosomally synthesized proteins or peptides that are secreted by bacteria that inhibit other closely related bacteria using various mechanisms $[8,9]$. Bacteriocins are divided into four major groups: class I, class II, class III, and class IV. The class I bacteriocins (lantibiotics) contain the first bacteriocin discovered from LAB, nisin [10]. Bacteriocins such as nisin are safe for human consumption since they are natural proteins and peptides that are degraded by the digestive enzymes in the stomach [11]. Nisin has "generally recognized as safe" (GRAS) status in the United States, granted by the United States Food and Drug Administration (FDA), for several applications in the food industry. It has been added as a food safety measure to a variety of foods in the world market, including dairy products, canned foods, salad dressings, sauces, and baby food. Nisin is effective against Gram-positive pathogens such as S. aureus, B. cereus, L. monocytogenes, and C. perfringens $[12,13]$.

Kefir, a fermented dairy beverage produced by the actions of the microflora encased in the "kefir grain" on the carbohydrates in the milk, originated thousands of years ago in the Caucasus mountain region between Europe and Russia. Containing many bacterial species already known for their probiotic properties, it has long been popular in Eastern Europe for its purported health benefits, where it is routinely administered to patients in hospitals and recommended for infants and the infirm. More than 30-50 species of yeasts (Saccharomyces sp., Kluyveromyces sp., Candida sp., Torulaspora sp., Cryptococcus sp., Pichia sp., etc.) and LAB (Lactobacillus sp., Lactococcus sp., Leuconostoc sp., etc.) have 
been isolated and identified from kefir grains [14,15]. Kefir grains have been shown to have regional differences in microbial composition, producing variability in the kefirs produced, due in part to local LAB finding a niche in the grains [16].

Kefir has been shown to contain a variety of natural antimicrobials, including bacteriocins, organic acids, hydrogen peroxide, and fatty acids. A Brazilian kefir product showed growth inhibition, measured as percent inhibition, against S. aureus ATCC 6538 (42.80\%-69.15\%), E. coli ATCC 11229 (30.73\%-59.89\%), S. typhi ATCC 6539 (44.99\%-73.05\%), L. monocytogenes ATCC 15313 (41.45\%-54.18\%) and B. cereus RIBO 1222-173-S4 (70.38\%-86.80\%) [17]. Another study investigated the antimicrobial activity of a Romanian kefir product against B. subtilis spp. spizizenii ATCC 6633, S. aureus ATCC 6538, E. coli ATCC 8739, Enterococcus faecalis ATCC 29212 and S. enteritidis ATCC 13076. The Romanian kefir showed strong antibacterial activity against Gram-negative and Gram-positive indicator strains when compared to neomycin sulfate and ampicillin [18]. The antimicrobial spectra of four types of kefirs (A, L, M, and S) from South Korea were determined in another study. With kefir A, B. cereus ATCC 14579, E. coli ATCC 25922, S. enterica serovar Enteritidis FDA, Pseudomonas aeruginosa ATCC 15522, and Cronobacter sakazakii ATCC 29544 were inhibited. B. cereus ATCC 14579, S. aureus ATCC 6538, E. coli ATCC 25922, S. enterica serovar Enteritidis FDA, P. aeruginosa ATCC 15522, and C. sakazakii ATCC 29544 were inhibited to different extents by kefirs L, M, and S. L. monocytogenes ATCC 51776 was only inhibited by kefir M [19].

To our knowledge, comparisons among international artisanal kefirs regarding their antimicrobial activities against select foodborne pathogens have not been reported. For this study, we hypothesized that international artisanal kefirs have diverse microflora, generating distinctive bacteriocin content, resulting in varied levels of antimicrobial activities. The objectives of our study were to 1) compare the antimicrobial activity of artisanal kefirs from Fusion Tea (A), Britain (B), the Caucuses region (C), Ireland (I), Lithuania (L), and South Korea (K) against select foodborne pathogens, and 2) examine whether the antimicrobial effect is due to bacteriocin production or other antimicrobials present in kefir.

\section{Materials and Methods}

\subsection{Artisanal Kefir Preparation for Determining Kefir Antimicrobial Activity}

Six types of artisanal kefir grains originating from Britain (B; Etsy Inc., Brooklyn, New York, NY, USA), the Caucuses (C; Etsy Inc., Brooklyn, New York, NY, USA), Ireland (I; Etsy Inc., Brooklyn, New York, NY, USA), Lithuania (L; Etsy Inc., Brooklyn, New York, NY, USA), South Korea (K) [19], and a compilation of blended world-sourced grains (A; Fusion Tea, Amazon, Seattle, WA, USA) were used in this study. Kefir grains were examined to evaluate their similarities and differences in shape, appearance, texture, and size while kefir products were evaluated for their flavor, aroma, and texture.

Artisanal kefir products were prepared using traditional methods. Kefir grains were inoculated into pasteurized whole milk daily for at least one week before any experiment. Kefir grains were inoculated $(10 \%(\mathrm{w} / \mathrm{v}))$ into whole pasteurized milk and the resulting mixture was incubated at $22-24{ }^{\circ} \mathrm{C}$ for $24 \mathrm{~h}$. The fermentation process was stopped when the $\mathrm{pH}$ reached 3.9-4.1 as measured by a calibrated PB Basic Meter (Denver Instrument, Bohemia, NY, USA). A clean plastic strainer with $1 \mathrm{~mm}$ pore size was used to separate the grains from kefir products. Designated plastic strainers were used for each kefir product/grains to avoid cross-contamination. Once separated, the kefir grains were inoculated $(10 \%(\mathrm{w} / \mathrm{v}))$ into a new batch of whole pasteurized milk to maintain their activity. The resulting kefir products were centrifuged at $10,000 \times g$ for 15 min at $4{ }^{\circ} \mathrm{C}$ using an Avanti J-17 high-speed centrifuge (Beckman Coulter, Inc., Palo Alto, CA, USA) to remove solids. Filtration through a Millex filter (Millipore Corporation, Bedford, MA, USA) with $45 \mu \mathrm{m}$ pore size was used to sterilize the samples. The filter-sterilized kefir samples were tested for their antimicrobial activities immediately. 


\subsection{Protein Concentration Measurements}

The total protein concentration was used as a measure to standardize artisanal kefir samples. A Bio-Rad Protein Assay Kit (Bio-Rad Laboratories, Hercules, CA, USA) was used to determine the total protein concentration in kefir samples. A standard procedure for microtiter plates was used with bovine serum albumin (standard II). Absorbance was measured at $595 \mathrm{~nm}$ using a microtiter plate reader (SpectraMax 190, Molecular Devices, San Jose, CA, USA). Kefir samples were examined in triplicate to determine the total protein concentration.

\subsection{Bacterial Strains, Microbiological Media, and Growth Conditions}

Bacterial strains used in the study were obtained from American Type Culture Collection (ATCC; Manassas, VA, USA), National Collection of Dairy Organisms (NCDO; now National Collection of Food Bacteria (NCFB); Scotland) and our in-house culture collection. Lactobacillus plantarum NCDO 995 and Micrococcus luteus ATCC 10420 were used as the non-pathogenic indicator strains. M. luteus was selected for its sensitivity to bacteriocins [20]. Lb. plantarum is also sensitive to bacteriocins produced by closely related LAB [21]. E. coli ATCC 12435 is not sensitive to bacteriocins from LAB and thus was used as a negative control. The pathogenic indicator strains included S. enterica serovar Enteritis ATCC 13076, S. aureus ATCC 25923, B. cereus ATCC 14579, and L. monocytogenes CWD 1198. Frozen stocks were maintained in sterile glycerol (25\%) and tryptic soy broth (TSB, Criterion, Hardy Diagnostics, Santa Maria, CA, USA) or Lactobacillus MRS broth (Remel, Thermo Fisher Scientific, Lenexa, KS, USA) and kept at $-80{ }^{\circ} \mathrm{C}$. Prior to experiments, all indicator organisms were streaked onto tryptic soy agar (TSA) or Lactobacillus MRS agar (for Lb. plantarum NCDO 995) and incubated at their optimum growth temperature. The following selective media were used to streak the pathogenic indicators for isolation as needed: Xylose Lysine Deoxycholate agar (XLD) for S. enterica serovar Enteritis ATCC 13076, Mannitol Yolk Polymyxin (MYP) agar for B. cereus ATCC 14579, Baird Parker agar (BPA) for S. aureus ATCC 25923, and HardyCHROM Listeria for L. monocytogenes. XLD, MYP, BPA, and HardyCHROM Listeria were obtained from Hardy Diagnostics (Santa Maria, CA, USA). The resulting single colonies on selective media were picked and inoculated into TSB and incubated for $24 \mathrm{~h}$. The incubation temperature used for Lb. plantarum NCDO 995, S. enterica serovar Enteritis ATCC 13076, S. aureus ATCC 25923, and L. monocytogenes CWD 1198 was 35-37 ${ }^{\circ}$ C. B. cereus ATCC 14579 and M. luteus ATCC 10420 cultures were incubated at $30^{\circ} \mathrm{C}$. M. luteus ATCC 10420 was incubated while shaking at $200 \mathrm{rpm}$ in an orbital shaking incubator.

\subsection{Detection of Antimicrobial Activity in Artisanal Kefirs}

The agar-well-diffusion method [20] with some modifications was used to study the antimicrobial activity of filter-sterilized artisanal kefir samples. Soft Lactobacillus MRS and TSA, containing $0.75 \%$ agar, were inoculated $\left(10^{7}-10^{8} \mathrm{CFU} / \mathrm{mL}\right.$ ) with the indicator (non-pathogenic and pathogenic) organisms. Bacterial growth curves, generated for all indicator organisms, were used for determining accurate inoculum levels. Filter-sterilized kefir samples were obtained as described above. The wells generated with sterile plastic Pasteur pipettes in soft agar were filled with 100, 150, 200, and $250 \mu \mathrm{L}$ of filter-sterilized kefir samples. Nisin (1000 IU/mg) and polylysine (1200 IU/mg), purchased from Zhengzhou Bainafo Bioengineering Co., Ltd. (Zhengzhou City, China), were used as positive bacteriocin controls at $220 \mathrm{IU}$ and $200 \mathrm{IU}$, respectively, and in a volume of $100 \mu \mathrm{L}$. Sterilized distilled water (DI) was used as a negative control, also in a volume of $100 \mu \mathrm{L}$. Lactobacillus MRS and TSA plates with wells containing filter-sterilized kefir samples, bacteriocin controls, and sterile DI water were incubated for $24 \mathrm{~h}$ at $30^{\circ} \mathrm{C}$ or $37^{\circ} \mathrm{C}$ depending on the optimum growth temperature of the indicator strains. Following the incubation, the diameter of clear zones was measured (in $\mathrm{mm}$ ) using a ruler. Two independent experiments, each in duplicate, were performed for any given kefir sample. 
2.5. Ruling-Out Any Antimicrobial Activity Due to Organic Acids, Hydrogen Peroxide, and Free Fatty Acids Produced in Artisanal Kefir

\subsubsection{Artisanal Kefir Preparation}

The Fusion Tea, Irish, and South Korean kefirs (A, I, and K) were selected for this study due to their high antibacterial activity observed in experiments using the agar-well-diffusion method. Artisanal kefir samples were prepared as mentioned above (2.1).

\subsubsection{Bacterial Strains, Microbiological Media, and Growth Conditions}

Bacterial strains, microbiological media, and growth conditions were the same as described above.

\subsubsection{Detection of Antimicrobial Activity Due to Bacteriocin Production in Artisanal Kefir}

The agar-well-diffusion method was used to detect antimicrobial activity due to bacteriocins present in artisanal kefir samples following the protocol by Dimitrieva-Moats and Ünlü (2011) and Ünlü et al. (2015) $[20,21]$ with some modifications. Artisanal kefir samples were prepared as mentioned above, filter sterilized, and $\mathrm{pH}$ adjusted to 6.0 using $\mathrm{NaOH}(5 \mathrm{M})$. Sterile bovine liver catalase (2000-5000 U/mg protein), Aspergillus oryzae lipase ( $\geq 100,000 \mathrm{U} / \mathrm{g})$, and Proteinase K from Tritirachium album ( $\geq 30$ units $/ \mathrm{mg}$ ), all of which were purchased from Sigma Aldrich (Saint Louis, MO, USA), were added to sterile kefir samples A, K, and I at a final concentration of $1 \mathrm{mg} / \mathrm{mL}$. $\beta$-glycerophosphate (Sigma Aldrich, Saint Louis, MO, USA) was added to sterile kefir samples A, $\mathrm{K}$, and $\mathrm{I}$ at $1 \%(\mathrm{w} / \mathrm{v})$. These mixtures were incubated at $37^{\circ} \mathrm{C}$ for $1 \mathrm{~h}$. Sterile $\beta$-glycerophosphate was used to buffer artisanal kefir samples with $\mathrm{pH}$ adjusted to 6.0. Bovine liver catalase and lipase from Aspergillus oryzae were used to degrade hydrogen peroxide and free fatty acids, respectively. Proteinase K from Tritirachium album ( $\geq 30$ units/mg) was used to break down bacteriocins, which are proteinaceous, and thus confirm their contribution to antimicrobial activity in kefir. Indicator strains (100 $\mu \mathrm{L}$ of cultures containing $\left.10^{8}-10^{9} \mathrm{CFU} / \mathrm{mL}\right)$ were spread onto soft TSA agar $(0.75 \%$ agar $(\mathrm{w} / \mathrm{v}))$. Several wells with a diameter of $7 \mathrm{~mm}$ were formed with sterile plastic Pasteur pipettes and the filter-sterilized kefir samples $(100 \mu \mathrm{L})$, with and without treatments, were added to the wells. Nisin and polylysine were used as positive bacteriocin controls at $220 \mathrm{IU}$ and $200 \mathrm{IU}$, respectively, and in a volume of $100 \mu \mathrm{L}$. Sterilized distilled water (DI) was used as a negative control in the volume of $100 \mu \mathrm{L}$. Plates were incubated overnight at $30^{\circ} \mathrm{C}$ or $37^{\circ} \mathrm{C}$ depending on the indicator strain. The diameter (in $\mathrm{mm}$ ) of clear zones was measured using a ruler. Two independent experiments, each in duplicate, were performed for any given kefir sample.

\subsection{Statistical Analysis}

For the detection of the antimicrobial activity in artisanal kefirs, the experiment was a completely random design. A three-way ANOVA was used for the following: indicator organisms, kefir types, kefir volumes and their interactions, followed by Tukey's multiple comparison procedure using $\mathrm{R}$ (R Studio Inc., Boston, MA, USA). For ruling out any antimicrobial activity due to organic acids, hydrogen peroxide and free fatty acids produced in kefir, a three-way ANOVA was used as well, followed by Tukey's multiple comparison procedure using $R$. The statistically significant difference was determined by cut-off for significance level at $5 \%$ (i.e., $p<0.05$ ).

\section{Results}

\subsection{Artisanal Kefir Products and Kefir Grains Description}

Artisanal kefir products and grains were described in Table 1. The kefir grains sizes ranged from $>1 \mathrm{~mm}$ to $50 \mathrm{~mm}$ depending on the origin. The smallest grains were from Ireland while the largest grains were from Britain. Kefir products differed in their flavor and aroma, as indicated in Table 1. 
Table 1. Artisanal kefir origin, source, grains' description and products' description.

\begin{tabular}{|c|c|c|c|}
\hline Kefir Origin & Source & Grains' Description & Products' Description \\
\hline Lithuania & Etsy Inc. & $\begin{array}{l}\text { Cauliflower-like appearance, off-white } \\
\text { to pale yellow, medium size }(1-10 \mathrm{~mm}) \\
\text { and firm grains }\end{array}$ & Mild, smooth, and not sour (sweet) \\
\hline Ireland & Etsy Inc. & Soft, small size (>1 mm) grains & $\begin{array}{l}\text { Mild, sweet and pleasant taste, } \\
\text { smooth, sweet aroma, fresh, } \\
\text { and cheesy }\end{array}$ \\
\hline The Caucuses region & Etsy Inc. & $\begin{array}{l}\text { Cauliflower-like appearance, off-white } \\
\text { to pale yellow, size } 2-10 \mathrm{~mm} \text {, firm, } \\
\text { rubbery with smooth grains }\end{array}$ & Earthy, cheesy aroma, and sour taste \\
\hline South Korea & [19] & Soft, curling, size $2-10 \mathrm{~mm}$ & Earthy, cheesy aroma, and sour taste \\
\hline Britain & Etsy Inc. & $\begin{array}{l}\text { Cauliflower-like appearance, small to } \\
\text { large size (2.5-50 mm), rubbery, firm, } \\
\text { smooth grains }\end{array}$ & $\begin{array}{l}\text { Creamy, earthy, cheesy aroma, } \\
\text { slightly sour }\end{array}$ \\
\hline Fusion Tea & Amazon & $\begin{array}{l}\text { Cauliflower-like appearance, off-white } \\
\text { to pale yellow, mixed sizes }(2-7 \mathrm{~mm}), \\
\text { firm, rubbery textured grains }\end{array}$ & $\begin{array}{l}\text { Smooth, mild sour, creamy, pleasant, } \\
\text { and fresh, sweet, yeasty aroma }\end{array}$ \\
\hline
\end{tabular}

\subsection{The Antimicrobial Activity Spectra of Filter-Sterilized Artisanal Kefirs}

\subsubsection{Protein Concentration}

All artisanal kefir samples tested were standardized based on total protein content (0.5 mg/mL kefir).

3.2.2. The Antimicrobial Activity Spectra of Filter-Sterilized Artisanal Kefirs Determined by the Agar Well Diffusion Method

As anticipated, nisin and polylysine controls inhibited the growth of all pathogenic and non-pathogenic indicator organisms excluding E. coli ATCC 12435, a non-pathogenic indicator organism used as the negative control (Figure $1 \mathrm{a}-\mathrm{g}$ ). Nisin showed the largest inhibition zone (33 mm) against Lb. plantarum NCDO 995 (Figure 1b). Polylysine showed the largest inhibition zone $(17 \mathrm{~mm})$ against M. luteus ATCC 10420 (Figure 1c).

E. coli ATCC 12435, the non-pathogenic indicator organism used as the negative control, was not sensitive to any artisanal kefirs (Figure 1a). M. luteus and Lb. plantarum, non-pathogenic indicators, were sensitive to nisin, polylysine, and all artisanal kefirs (A, B, C, I, K, and L) used at a range of volumes (100-250 $\mu \mathrm{L}$ ) (Figure 1b,c). Lb. plantarum inhibition zones observed with artisanal kefirs $(250 \mu \mathrm{L})$ were $8.5-16 \mathrm{~mm}$ (Figure $1 \mathrm{~b})$. M. luteus inhibition zones observed with artisanal kefirs $(250 \mu \mathrm{L})$ were 14-20.5 mm (Figure 1c). Results obtained with non-pathogenic indicators confirmed that experiments employing the agar well diffusion method worked well.

All artisanal kefirs, A, B, C, I, K, and L, showed significant $(p<0.002)$ antimicrobial activity against pathogenic indicators (Figure $1 \mathrm{~d}-\mathrm{g}$ ). Kefirs $\mathrm{A}, \mathrm{B}$, and I inhibited all pathogenic indicators at different levels $(p<0.001$ ) (Figure 1d-g). Kefirs C, K, and L inhibited all pathogenic indicators (Figure 1d-g), except $S$. aureus ATCC 25923 (Figure 1f), which was inhibited by kefirs A, B, and I, compared to the negative control E. coli ATCC $12435(p<0.05)$. S. aureus ATCC 25923 displayed inhibition zones with increasing kefir volumes (150-250 $\mu \mathrm{L}$ ) with kefirs A, B, and I (Figure 1f). S. enterica serovar Enteritis ATCC 13076 was inhibited by all kefir types $(p<0.05)$, with inhibition zones of 7-10 mm at $250 \mu \mathrm{L}$ volume. L. monocytogenes CWD 1198 was inhibited the most by kefir I, K, and B $(p<0.05)$, with an inhibition zone of 12.5-14 mm, and at a volume of $250 \mu \mathrm{L}$ (Figure 1e). The antilisterial effect of kefir I and kefir K (used at $250 \mu \mathrm{L}$ ) was equal to the antilisterial activity of nisin $(100 \mu \mathrm{L}=220 \mathrm{IU}$ ) (Figure 1e). L. monocytogenes CWD 1198 displayed increasing inhibition zones with increasing kefir volumes (150-250 $\mu \mathrm{L}$ ) with kefirs A, B, C, I, and K but not kefir L (Figure 1e). With kefir L, L. monocytogenes CWD 1198 inhibition zone was constant $(7 \mathrm{~mm})$ regardless of the kefir $\mathrm{L}$ volume applied (Figure 1e). B. cereus showed the same inhibition zone $(7 \mathrm{~mm})$ with all artisanal kefirs, regardless of the kefir volumes used (100-250 $\mu \mathrm{L})$, and with both positive bacteriocin controls (100 $\mu \mathrm{L}$ each) (Figure 1d). 

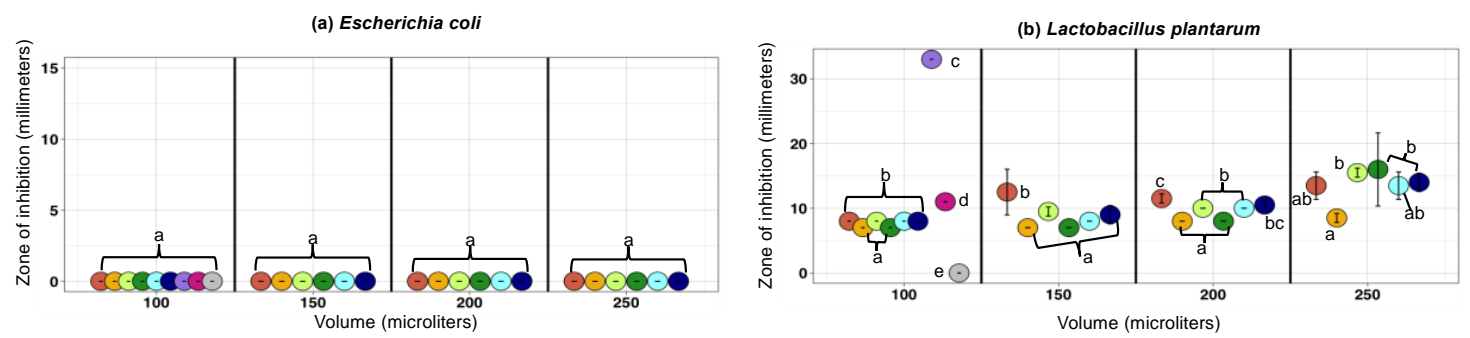

(c) Micrococcus luteus
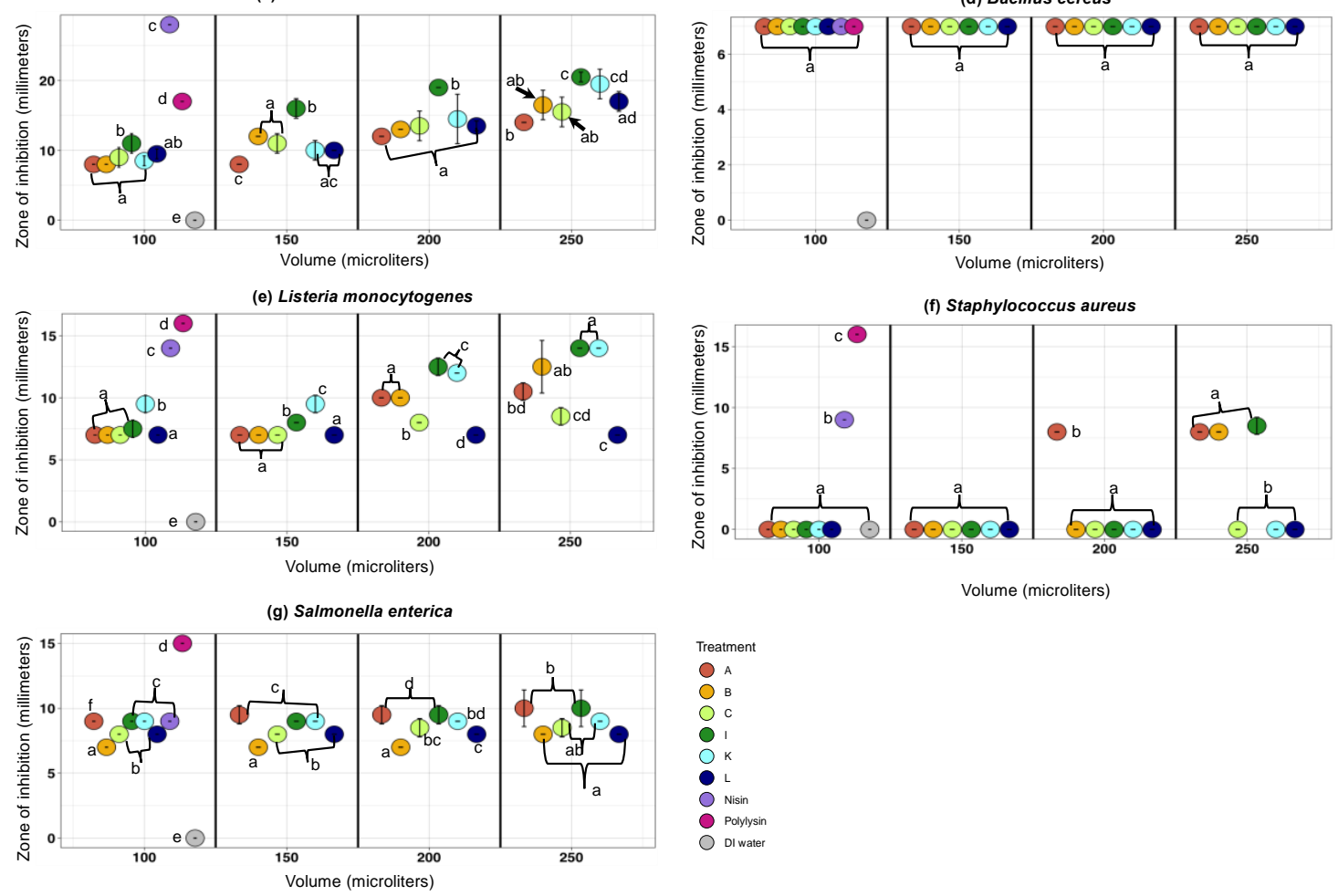

Figure 1. Comparison of the antimicrobial activity spectra of artisanal kefirs from Fusion Tea (A, Amazon); Britain (B); the Caucasus region (C); Ireland (I); South Korea (K); and Lithuania (L) against (a) Escherichia coli ATCC 12435, (b) Lactobacillus plantarum NCDO 995, (c) Micrococcus luteus ATCC 10420, (d) Bacillus cereus ATCC 14579, (e) Listeria monocytogenes CWD 1198, (f) Staphylococcus aureus ATCC 25923, and (g) Salmonella enterica serovar Enteritidis ATCC 13076 using the agar well diffusion method. A range of filter-sterilized artisanal kefir volumes $(100 \mu \mathrm{L}, 150 \mu \mathrm{L}, 200 \mu \mathrm{L}$, and $250 \mu \mathrm{L})$ were placed inside the wells. Nisin (N; $220 \mathrm{IU})$ and polylysin (P; $200 \mathrm{IU})$ were used as positive controls in a volume of $100 \mu \mathrm{L}$. Sterilized DI water $(100 \mu \mathrm{L})$ was used as a negative control. The diameter of the inhibition zones was measured in $\mathrm{mm}$. All experiments were conducted two independent times and each time in duplicate. Different letters (a-f) indicate statistical pairwise comparisons between the treatments within each volume performed by post-hoc Tukey's multiple comparison procedure. The same letter indicates no significant difference between the treatments within each volume.

3.3. Ruling-Out Any Antimicrobial Activity Due to Organic Acids, Hydrogen Peroxide, and Free Fatty Acids Produced in Artisanal Kefir

$\mathrm{LAB}$ are known to produce antibacterial metabolites, including bacteriocins, organic acids, $\mathrm{H}_{2} \mathrm{O}_{2}$, and fatty acids. Application of filter-sterilized artisanal kefir samples treated with proteinase $\mathrm{K}$ from Tritirachium album, $\beta$-glycerophosphate, bovine liver catalase, and lipase from Aspergillus oryzae in agar well diffusion experiments allowed us to rule out any antimicrobial activity due to these metabolites produced by LAB in kefir. 
As anticipated, E. coli ATCC 12435, a non-pathogenic organism used as a negative control, was not sensitive to any artisanal kefir (A, I, and K), untreated or treated with proteinase $\mathrm{K}$, $\beta$-glycerophosphate, catalase, and lipase. (Figure $2 \mathrm{a}-\mathrm{c}$ ). This confirms the antimicrobial activity results obtained for kefirs A, I, and K described in Section 3.2.2.

\section{(a) Kefir A}

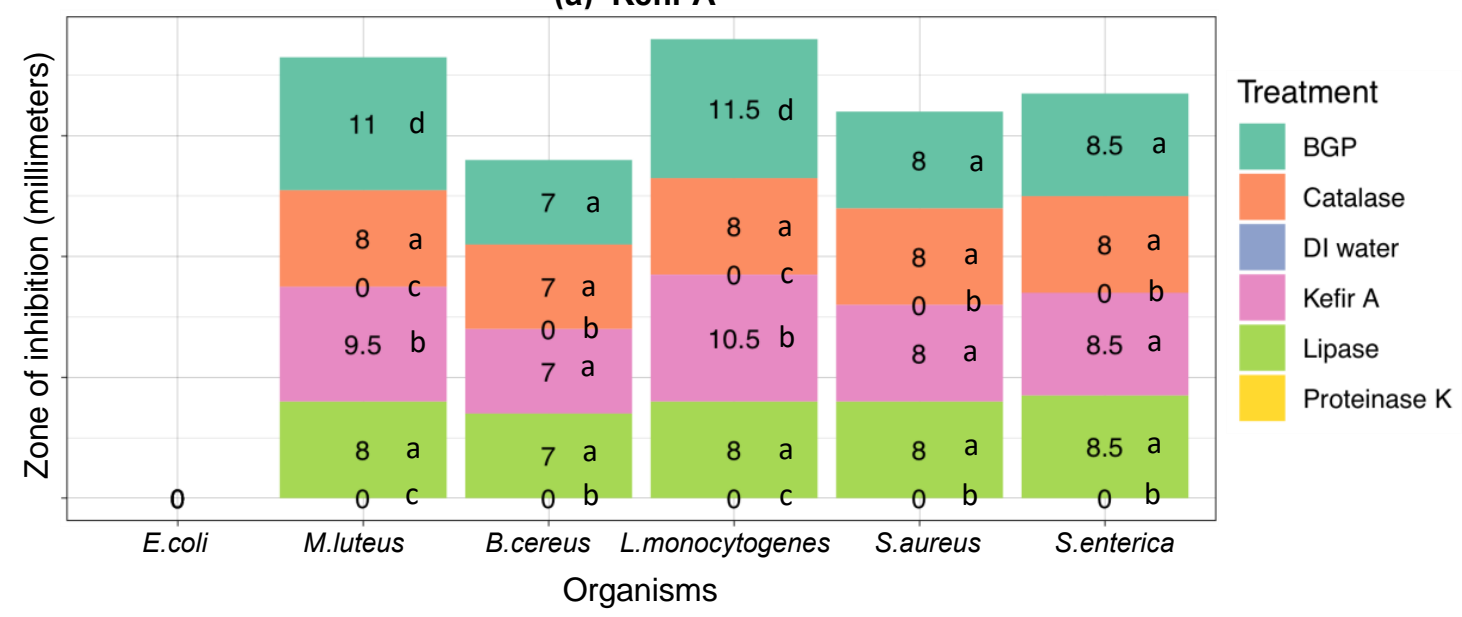

(b) Kefir I

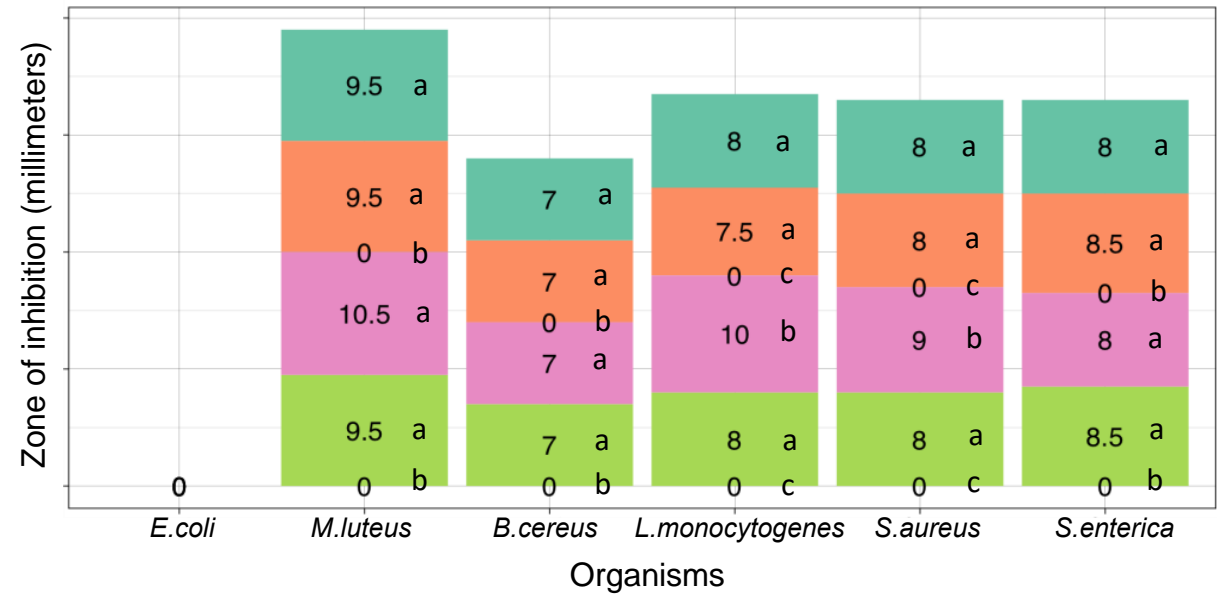

Treatment

BGP

Catalase

DI water

Kefir I

Lipase

Proteinase $\mathrm{K}$

(c) Kefir K

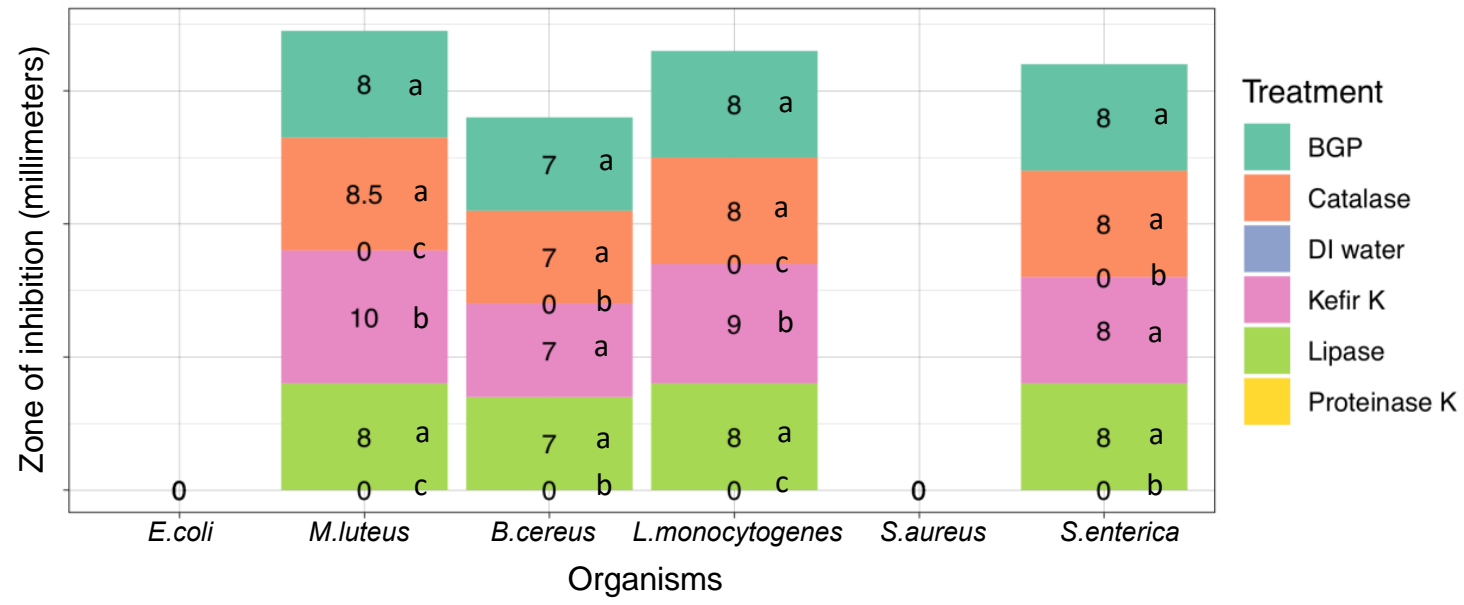

Figure 2. Bacteriocin-based antimicrobial activity in filter-sterilized artisanal kefir samples from (a) Fusion Tea (Kefir A), (b) Ireland (Kefir I), and (c) South Korea (Kefir K) against select indicator strains 
using $\beta$-glycerophosphate (BGP, teal), bovine liver catalase (coral), lipase from Aspergillus oryzae (lime green), and proteinase $\mathrm{K}$ from Tritirachium album (yellow). The agar well diffusion method was used. Sterile DI water (blue) was used as the negative control. Wells generated in each plate contained filter-sterilized artisanal kefir product $(100 \mu \mathrm{L})$ with or without the additives mentioned above. The diameter of the inhibition zones was measured in $\mathrm{mm}$ after incubation for $24 \mathrm{~h}$ at 37 or $30^{\circ} \mathrm{C}$. Different letters $(\mathbf{a}-\mathbf{c})$ indicate statistical pairwise comparisons between the treatments for a given organism performed by post-hoc Tukey's multiple comparison procedure. The same letter indicates no significant difference between treatments for a given organism.

No bacterial inhibition zones were observed with M. luteus or any pathogenic indicators when proteinase K-treated kefirs A, I, and K were used $(p<0.001)$, confirming that the majority of the antibacterial activity observed was due to bacteriocins with proteinaceous nature (Figure 2a-c). As expected, proteinase K-treated nisin and polylysin, used as bacteriocin controls, did not show any inhibitory activity against $M$. luteus or any pathogenic indicators.

M. luteus, a non-pathogenic organism used as a positive control, was sensitive to all untreated kefirs (A, I, and K) and all catalase-, lipase-, and $\beta$-glycerophosphate-treated kefirs (A, I, and K) (Figure 2a-c). M. luteus inhibition zones observed with untreated kefir A were $9.5 \mathrm{~mm}$ while the catalase-, lipase-, and $\beta$-glycerophosphate-treated kefir A samples were 8,8 , and $11 \mathrm{~mm}$, respectively, indicating that both $\mathrm{H}_{2} \mathrm{O}_{2}$ and free fatty acids made contributions to total antimicrobial activity (Figure 2a). The increase in antimicrobial activity with $\beta$-glycerophosphate-treated kefir A can be explained by an increase in bacteriocin(s) activity at the higher $\mathrm{pH}$ achieved with $\beta$-glycerophosphate addition to kefir A. While untreated kefir I resulted in an inhibition zone of $10.5 \mathrm{~mm}$ for M. luteus, the catalase-, lipase-, and $\beta$-glycerophosphate-treated kefir I samples resulted in an inhibition zone of $9.5 \mathrm{~mm}$, which was not a significant difference $(p>0.05)$ (Figure 2b). M. luteus was inhibited by untreated kefir K, with an inhibition zone of $10 \mathrm{~mm}$, as well as the catalase-, lipase-, and $\beta$-glycerophosphate-treated kefir $\mathrm{K}$ samples with inhibition zones of $8.5,8$, and $8 \mathrm{~mm}$, respectively. These results show a very similar contribution to the total antimicrobial activity by $\mathrm{H}_{2} \mathrm{O}_{2}$, free fatty acids, and organic acids (Figure 2c).

The untreated and the catalase-, lipase-, and $\beta$-glycerophosphate-treated kefir A samples resulted in the inhibition zones of 8 and $7 \mathrm{~mm}$ for S. aureus and B. cereus, respectively, indicating that the bacteriocin activity is responsible for the antimicrobial activity against the two pathogenic indicator organisms (Figure 2a). While the untreated kefir A sample resulted in an inhibition zone of $10.5 \mathrm{~mm}$ against L. monocytogenes, the catalase-, lipase-, and $\beta$-glycerophosphate-treated kefirs resulted in the inhibition zones of 8,8 , and $11.5 \mathrm{~mm}$, respectively (Figure 2a). These observations indicate that L. monocytogenes was inhibited mostly by bacteriocins in kefir A, but organic acids, free fatty acids, and $\mathrm{H}_{2} \mathrm{O}_{2}$ made contributions to the total inhibition. The individual contributions of free fatty acids and $\mathrm{H}_{2} \mathrm{O}_{2}$ to the total antimicrobial activity in kefir A were identical as per these results.

The bacteriocin activity in Kefir I was solely responsible for the antimicrobial activity observed against B. cereus (Figure 2b). Because, the untreated and the catalase-, lipase-, and $\beta$-glycerophosphate-treated kefir I samples resulted in the identical inhibition zones of $7 \mathrm{~mm}$ against $B$. cereus. In the case of $S$. aureus, the catalase-, lipase-, and $\beta$-glycerophosphate-treated kefir I samples resulted in the inhibition zone of $8 \mathrm{~mm}$, which is $1 \mathrm{~mm}$ less than the inhibition zone $(9 \mathrm{~mm})$ observed with untreated kefir I (Figure 2b). With L. monocytogenes, the catalase-, lipase-, and $\beta$-glycerophosphate-treated kefir I samples resulted in the inhibition zones of $7.5-8 \mathrm{~mm}$, which are smaller than the inhibition zone $(10 \mathrm{~mm}$ ) observed with untreated kefir I (Figure $2 b$ ). These results indicated that organic acids, free fatty acids, and $\mathrm{H}_{2} \mathrm{O}_{2}$ made identical contributions to the total inhibition of the two pathogens. An identical inhibition zone $(8 \mathrm{~mm})$ was observed with S. enterica serovar Enteritidis when using the untreated and $\beta$-glycerophosphate-treated kefir I, indicating that the total antimicrobial activity is due to bacteriocins in kefir I (Figure 2b). The S. enterica serovar Enteritidis inhibition zones of 8.25 and $8.75 \mathrm{~mm}$, observed with the lipase- and catalase-treated kefir I respectively, 
were slightly larger than the $8 \mathrm{~mm}$ zone observed with untreated kefir (Figure $2 \mathrm{~b}$ ). The difference was not statistically significant.

The untreated and the catalase-, lipase-, and $\beta$-glycerophosphate-treated kefir K samples resulted in the inhibition zones of 8 and $7 \mathrm{~mm}$ for S. enterica serovar Enteritidis and B. cereus, respectively, illustrating that the bacteriocin activity in kefir $\mathrm{K}$ is solely responsible for the total antimicrobial activity against these two pathogens (Figure 2c). For L. monocytogenes, an inhibition zone of $8 \mathrm{~mm}$ was observed with the catalase-, lipase-, and $\beta$-glycerophosphate-treated kefir K samples while the untreated kefir $\mathrm{K}$ sample resulted in an inhibition zone of $9 \mathrm{~mm}$ (Figure 2c). Based on the results, the individual contribution of organic acids, free fatty acids, and $\mathrm{H}_{2} \mathrm{O}_{2}$ to total antimicrobial activity is identical. The untreated and the catalase-, lipase-, and $\beta$-glycerophosphate-treated kefir K samples did not exhibit any anti-staphylococcal activity (Figure 2c), confirming the results described for kefir $\mathrm{K}$ in Section 3.2.2.

\section{Discussion}

In the presented work, we explored the antimicrobial activity of international artisanal kefirs from Fusion Tea, Britain, the Caucuses region, Ireland, Lithuania, and South Korea and made comparisons among these kefirs regarding their antimicrobial activity. Based on our findings, antimicrobials with proteinaceous nature (e.g., bacteriocins) are responsible for the majority of antibacterial activity observed against the foodborne pathogens tested. To our knowledge, this is the first report in the literature that deals with such comparisons among international artisanal kefirs.

Our work targeted select foodborne pathogens, including L. monocytogenes, S. enterica serovar Enteritidis, S. aureus, and B. cereus, all known to be hazardous to human health. One of these pathogens, L. monocytogenes, is considered to be a major challenge for the food industry worldwide. In particular, refrigerated, ready-to-eat (RTE) foods pose a high listeriosis risk because refrigeration offers an environment in which L. monocytogenes can outcompete other mesophilic microorganisms. Another target pathogen, B. cereus, especially psychrotrophic strains, are problematic in dairy foods for various reasons: (1) B. cereus readily spread from healthy and decaying plants and soil to the cows and raw milk; (2) hydrophobic B. cereus spores attach to surfaces in dairy plants; B. cereus spores survive milk pasteurization, germinate in the absence of competitive microflora, and cause problems in milk products. Therefore, additional food preservation approaches need to be in place to ensure the safety of refrigerated foods. Biologically based preservation, through the use of LAB, can be used to enhance microbial food safety of refrigerated foods without modifying them. LAB are accepted by many countries in the world as "GRAS". LAB are also perceived by consumers in the world as "natural," "healthy," and "health-promoting".

LAB have been shown to produce bacteriocins that inhibit foodborne pathogens such as L. monocytogenes [22]. Kefir contains many LAB species known for their bacteriocin production and probiotic benefits $[16,23,24]$. Joao et al. tested kefir products from Brazil against $L$. monocytogenes ATCC 15313 and found 54.18\% inhibition when compared to that of the untreated control [17]. Our research findings are in agreement with that of Joao et al. in that kefir has antilisterial activity. In our work, all artisanal kefirs (A, B, C, I, K, and L) exhibited varying levels of inhibition against L. monocytogenes.

Artisanal kefir has been shown to exhibit various antimicrobial activities against foodborne pathogens and spoilage organisms [17-19]. Coconut milk inoculated with kefir grains from India showed antimicrobial and antifungal activity against E. coli, S. typhi, S. aureus, Saccharomyces cerevisiae, and Aspergillus niger [25]. Kefir originating from Argentina inhibited the growth of E. coli ATCC 11229, S. enterica serovar Enteritidis CIDCA 101, and B. cereus ATCC 10876 [26]. In our study, artisanal kefirs originating from six different regions of the world showed antimicrobial activity against select foodborne pathogens. Kim et al. compared the antimicrobial spectra of four types of kefirs from South Korea, which showed inhibition against select strains of B. cereus, S. enterica serovar Enteritidis, P. aeruginosa, C. sakazakii, and L. monocytogenes [19]. We showed that the same South Korean kefir 
$(\mathrm{K})$ inhibited all pathogenic indicator strains tested except $S$. aureus $(p<0.05)$. Our study supports the findings of Kim et al. in that South Korean kefir has a wide antimicrobial activity spectrum [19]. When compared to other kefirs in this study, the kefir from South Korea (K) showed the highest antimicrobial activity against $L$. monocytogenes when using the smallest volume (100 ul) of kefir product. The kefirs from Ireland, Britain, and Fusion Tea inhibited S. aureus $(p<0.05)$, in contrast to the South Korean kefir.

In our study, kefir K exhibited antimicrobial activity against all foodborne pathogenic indicators, except $S$. aureus. Consequently, our goal is to carry out additional research on kefir $\mathrm{K}$ with emphasis on isolation and characterization of LAB and their bacteriocins and application of these bacteriocins as natural antimicrobials against L. monocytogenes, B. cereus, and S. enterica. In addition, kefir A and I showed the highest inhibition zones against $S$. aureus. Therefore, we are interested in further studying kefir A and kefir I as sources of natural antimicrobials against $S$. aureus.

\section{Conclusions}

Consumers demand natural, health-promoting, and nutritious food. Chemical additives have been extensively used in food preservation but their safety and impact on human health continue to be under discussion. The food industry desires to replace chemical preservatives with natural biopreservatives. Kefir has a natural antimicrobial activity due to the presence of LAB with bacteriocin production capability. In this study of artisanal kefirs from different countries, we have elucidated that bacteriocin production is the main reason for these kefirs' antimicrobial activity against select foodborne pathogens. Based on our findings in this study, kefir-based antimicrobials are being explored in our laboratory as promising natural biopreservatives in model food systems.

Author Contributions: Conceptualization, G.Ü.; Methodology, A.S., M.B.B., B.N., and G.Ü.; Formal Analysis, A.S., M.B.B., and G.Ü.; Investigation, A.S., B.N., and G.Ü.; Resources, A.S., M.B.B., B.N., and G.Ü; Writing-Original Draft Preparation, A.S.; Writing—Review and Editing, A.S., M.B.B., B.N., and G.Ü.; Supervision, G.Ü.; Project Administration, G.Ü.; Funding Acquisition, A.S. and G.Ü. All authors have read and agreed to the published version of the manuscript.

Funding: This research was funded by the United States Department of Agriculture (USDA) National Institute of Food and Agriculture (NIFA) Hatch project [1015890)] and the BUILD Dairy Program of Utah State University (17597). The APC was funded by the BUILD Dairy Program of Utah State University (17597).

Acknowledgments: We thank Saudi Arabian Cultural Mission for their support of Abrar Sindi. We thank Glenn Grout and Samantha Mamer for their assistance in the lab. We express our appreciation to Mete Yüksel for his assistance with the figures.

Conflicts of Interest: The authors declare no conflict of interest. The sponsors had no role in the design, execution, interpretation, or writing of the study.

\section{References}

1. Kirk, M.D.; Pires, S.M.; Black, R.E.; Caipo, M.; Crump, J.A.; Devleesschauwer, B.; Dopfer, D.; Fazil, A.; Fischer-Walker, C.L.; Hald, T.; et al. Correction: World Health Organization Estimates of the Global and Regional Disease Burden of 22 Foodborne Bacterial, Protozoal, and Viral Diseases, 2010: A Data Synthesis. PLoS Med. 2015, 12, e1001940. [CrossRef]

2. The World Bank. Food-Borne Illnesses Cost US\$ 110 Billion Per Year in Low- and Middle-Income Countries. 2018. Available online: https://www.worldbank.org/en/news/press-release/2018/10/23/food-borne-illnessescost-us-110-billion-per-year-in-low-and-middle-income-countries. (accessed on 3 March 2020).

3. Scallan, E.; Griffin, P.M.; Angulo, F.J.; Tauxe, R.V.; Hoekstra, R.M. Foodborne illness acquired in the United States-unspecified agents. Emerg. Infect. Dis. 2011, 17, 16-22. [CrossRef]

4. Scallan, E.; Hoekstra, R.M.; Angulo, F.J.; Tauxe, R.V.; Widdowson, M.A.; Roy, S.L.; Jones, J.L.; Griffin, P.M. Foodborne illness acquired in the United States-Major pathogens. Emerg. Infect. Dis. 2011, 17, 7-15. [CrossRef] 
5. Scallan, E.; Hoekstra, R.M.; Mahon, B.E.; Jones, T.F.; Griffin, P.M. An assessment of the human health impact of seven leading foodborne pathogens in the United States using disability adjusted life years. Epidemiol. Infect. 2015, 143, 2795-2804. [CrossRef]

6. National Center for Emerging and Zoonotic Infectious Diseases. Estimated Annual Number of Episodes of Illnesses Caused by 31 Pathogens Transmitted Commonly by Food, United States. Available online: https://www.cdc.gov/foodborneburden/pdfs/scallan-estimated-illnesses-foodborne-pathogens.pdf (accessed on 3 March 2020).

7. Matthews, K.R.; Kniel, K.E.; Montville, T.J. Food Microbiology: An Introduction, 4th ed.; John Wiley \& Sons: Hoboken, NJ, USA, 2017.

8. Montville, T.J.; Matthews, K.R.; Kniel, K.E. Food Microbiology an Introduction, 3rd ed.; ASM Press: Washington, DC, USA, 2012; p. 419.

9. Mills, S.; Serrano, L.M.; Griffin, C.; O'Connor, P.M.; Schaad, G.; Bruining, C.; Hill, C.; Ross, R.P.; Meijer, W.C. Inhibitory activity of Lactobacillus plantarum LMG P-26358 against Listeria innocua when used as an adjunct starter in the manufacture of cheese. Microb. Cell Fact. 2011, 10 (Suppl. 1), S7. [CrossRef]

10. Gharsallaoui, A.; Joly, C.; Oulahal, N.; Degraeve, P. Nisin as a Food Preservative: Part 2: Antimicrobial Polymer Materials Containing Nisin. Crit. Rev. Food Sci. Nutr. 2016, 56, 1275-1289. [CrossRef]

11. Nivedita, S.; Riti, K.; Neha, G.; Ranjana, K. Purification and Characterization of Bacteriocin Produced by Bacillus subtilis R75 Isolated from Fermented Chunks of Mung Bean (Phaseolus radiatus). Food Technol. Biotechnol. 2011, 49, 169-176.

12. Badaoui Najjar, M.; Kashtanov, D.; Chikindas, M.L. Epsilon-poly-L-lysine and nisin A act synergistically against Gram-positive food-borne pathogens Bacillus cereus and Listeria monocytogenes. Lett. Appl. Microbiol. 2007, 45, 13-18. [CrossRef]

13. Jeevaratnam, K.; Jamuna, M.; Bawa, A.S. Biological preservation of foods- Bacteriocins of lactic acid bacteria. Indian J. Biotechnol. 2005, 4, 446-454.

14. Kolakowski, P. Ozimkiewicz, M. Restoration of kefir grains subjected to different treatments. Int. J. Dairy Technol. 2012, 65, 140-145. [CrossRef]

15. Nejati, F.; Junne, S.; Neubauer, P. A Big World in Small Grain: A Review of Natural Milk Kefir Starters. Microorganisms 2020, 8, 192. [CrossRef] [PubMed]

16. Nielsen, B.; Gürakan, G.C.; Ünlü, G. Kefir: A multifaceted fermented dairy product. Probiotics Antimicrob. Proteins 2014, 6, 123-135. [CrossRef]

17. Joao, S.; Tatiane, A.; Célia, F.; Simone, G. Evaluation of antagonistic activity of milk fermented with kefir grains of different origins. Braz. Arch. Biol. Technol. 2013, 56, 823-827.

18. Chifiriuc, M.C.; Cioaca, A.B.; Lazar, V. In vitro assay of the antimicrobial activity of kephir against bacterial and fungal strains. Anaerobe 2011, 17, 433-435. [CrossRef]

19. Kim, D.H.; Jeong, D.; Kim, H.; Kang, I.B.; Chon, J.W.; Song, K.Y.; Seo, K.H. Antimicrobial Activity of Kefir against Various Food Pathogens and Spoilage Bacteria. Korean J. Food Sci. Anim. Resour. 2016, 36, 787-790. [CrossRef] [PubMed]

20. Ünlü, G.; Nielsen, B.; Ionita, C. Production of Antilisterial Bacteriocins from Lactic Acid Bacteria in Dairy-Based Media: A Comparative Study. Probiotics Antimicrob. Proteins 2015, 7, 259-274. [CrossRef] [PubMed]

21. Dimitrieva-Moats, G.Y.; Ünlü, G. Development of Freeze-Dried Bacteriocin-Containing Preparations from Lactic Acid Bacteria to Inhibit Listeria monocytogenes and Staphylococcus aureus. Probiotics Antimicrob. Proteins 2012, 4, 27-38. [CrossRef] [PubMed]

22. Ünlü, G.; Nielsen, B.; Ionita, C. Inhibition of Listeria monocytogenes in Hot Dogs by Surface Application of Freeze-Dried Bacteriocin-Containing Powders from Lactic Acid Bacteria. Probiotics Antimicrob. Proteins 2016, 8, 102-110. [CrossRef] [PubMed]

23. Farag, M.A.; Jomaa, S.A.; El-Wahed, A.A.; El-Seedi, A.H.R. The Many Faces of Kefir Fermented Dairy Products: Quality Characteristics, Flavour Chemistry, Nutritional Value, Health Benefits, and Safety. Nutrients 2020, 12, 346. [CrossRef] [PubMed]

24. Plessas, S.; Nouska, C.; Mantzourani, I.; Kourkoutas, Y.; Alexopoulos, A.; Bezirtzoglou, E. Microbiological Exploration of Different Types of Kefir Grains. Fermentation 2017, 3, 1. [CrossRef] 
25. Lakshmi, T.S.; MaryPramela, A.; Iyer, P. Anti-microbial, anti-fungal and anti-carcinogenic properties of coconut milk kefir. Int. J. Home Sci. 2017, 3, 365-369.

26. Iraporda, C.; Abatemarco Junior, M.; Neumann, E.; Nunes, A.C.; Nicoli, J.R.; Abraham, A.G.; Garrote, G.L. Biological activity of the non-microbial fraction of kefir: Antagonism against intestinal pathogens. J. Dairy Res. 2017, 84, 339-345. [CrossRef] [PubMed] 